\title{
Múltiplos apressórios e tubos de anastomoses conidiais no processo infeccioso de Colletotrichum gloeosporioides em macieira
}

\author{
Leonardo Araujo; Marciel J. Stadnik (*) \\ Universidade Federal de Santa Catarina (UFSC), Departamento de Fitotecnia, Centro de Ciências Agrárias, 88040-900, Florianópolis \\ (SC), Brasil. \\ $\left(^{*}\right)$ Autor correspondente: stadnik@cca.ufsc.br
}

Recebido: 30/abril/2013; Aceito: 06/jun./2013

\begin{abstract}
Resumo
A Mancha Foliar de Glomerella (MFG), causada por Colletotrichum gloeosporioides, é uma doença emergente e destrutiva, da qual pouco se conhece sobre as relações patógeno/hospedeiro. O objetivo deste trabalho foi quantificar o número de apressórios por conídio e verificar a presença de Tubos de Anastomoses Conidiais (TAC) formados sobre folhas de macieira resistente e suscetível para MFG, inoculadas com dois isolados de C. gloeosporioides (MANE55 e MANE147). Os eventos iniciais de penetração de C. gloeosporioides foram semelhantes em ambos os genótipos, porém, o isolado MANE55 apresentou maior número de conídios germinados com múltiplos apressórios. Foi observado TAC sobre lesões da MFG para ambos os isolados em todos os intervalos de tempo.
\end{abstract}

Palavras-chave: mancha foliar de Glomerela, Malus domestica, resistência.

\section{Multiple appressoria and conidial anastomosis tubes in the infection process of Colletotrichum gloeosporioides on apple}

\section{Abstract}

The Glomerella Leaf Spot (GLS), caused by Colletotrichum gloeosporioides is an emerging and destructive plant disease, of which little is known about the relationship pathogen/host. The objective of this study was to quantify the number of appressoria per conidium and verify the presence of Conidial Anastomosis Tubes (CAT) formed on apple resistant and susceptible leaves to GLS, inoculated with two isolates of C. gloeosporioides (MANE55 and MANE147). The early penetration events of C. gloeosporioides were similar in both genotypes, but the isolated MANE55 showed a greater number of germinated conidia with multiple appressoria. CAT on lesions of GLS were observed for both the isolates at all time intervals.

Key words: glomerella leaf spot, Malus domestica, resistance.

A Mancha Foliar de Glomerella (MFG) causada por Colletotrichum gloeosporioides (Penz.) Penz. \& Sacc. é uma doença emergente da macieira (Malus domestica Borkh.) que ocorre durante veróes chuvosos e, sob tais condiçōes, pode causar severo desfolhamento (acima de $75 \%$ ), reduzindo o rendimento dos frutos e as reservas nutricionais das plantas (Becker, Katsurayama e Boneti, 2000; Gonzalez, Sutton e Correll, 2006). A "Gala", descendente do grupo "Golden Delicious", é altamente suscetível ao C. gloeosporioides, enquanto que as que descendem do grupo "Delicious", como "Fuji", apresentam resistência completa à MFG (Becker, Katsurayama e Boneti, 2000; Gonzalez, Sutton e Correll, 2006).

As fases iniciais do desenvolvimento de Colletotrichum sp. durante o processo de infecção são similares para todas as espécies. Através de sinais químicos e físicos, o conídio depositado inicia o processo de germinação, elongação do tubo germinativo e diferenciação em um apressório séssil ou pedicelado (Kolattukudy et al., 1995; Peres et al., 2005; Gonçalves e Stadnik, 2012). No entanto, a liberação de etileno durante a maturação de frutos pode induzir a formação de múltiplos apressórios em um único conídio de Colletotrichum (FLAISHMan e Kolattukudy, 1994; Kolattukudy et al., 1995).

Tubos de Anastomoses Conidiais (TAC) vêm sendo descritos na maioria dos Ascomicetos e em várias espécies de Colletotrichum (Roca, Read e Wheals, 2005). A fusão de TAC tem sido descrita em condiçôes in vitro, dentro de acérvulos e na superfície dos hospedeiros (Ishiakawa et al., 2010a; Mehrabi et al., 2011). TAC surgem de conídios, assim como tubos germinativos, 
mas diferem destes por serem mais finos, não ramificados e possuírem crescimento direcionado a outro conídio. A fusão de TAC entre conídios permite a troca de nutrientes, água, mitocôndrias, vacúolos e núcleos (RocA, READ e Wheals, 2005; IshiakaWA et al., 2010b). Além disso, TAC entre fungos facilitam a transferência horizontal de genes (THG), em nível intra e interespecífico. A THG é definida como a transmissão de genes entre organismos por outros mecanismos que excluem processos como meiose e mitose (tranferência vertical de genes) (Mehrabi et al., 2011).

Apesar de existirem informaçôes sobre a formação de múltiplos apressórios (Flaishman e Kolattukudy, 1994) e TAC em várias espécies de Colletotrichum (RocA, READ e Wheals, 2005), desconhece-se se tais fenômenos podem ocorrer no patossistema macieira-C. gloeosporioides. Desta forma, o objetivo deste trabalho foi quantificar o número de apressórios por conídio e verificar a presença de TAC durante o processo infeccioso de isolados de C. gloeosporioides em genótipos de macieira suscetíveis e resistentes à MFG.

Plântulas de macieira foram obtidas de sementes de maçã "Gala" polinizadas por "Fuji" (pólen doador) e cultivadas de acordo com Araújo e Stadnik (2011; 2013). Os genótipos dos segregantes suscetíveis e resistentes à MFG foram identificados por meio de um bioensaio em folha destacada, conforme metodologia descrita por ARAújo e STADNiK $(2011 ; 2013)$.

Os isolados MANE55 e MANE147 de C. gloeosporioides, provenientes de Vacaria (RS) e Urubici (SC), respectivamente, foram mantidos em meio BDA. Após dez dias de incubação a $25{ }^{\circ} \mathrm{C}$ e $12 \mathrm{~h}$ de fotoperíodo, as colônias foram raspadas e a concentração da suspensão ajustada para $3 \times 10^{5}$ conídios $\mathrm{mL}^{-1}$ de $C$. gloeosporioides. Plântulas suscetíveis e resistentes com 60 dias de idade e aproximadamente 10 a 15 folhas expandidas foram inoculadas por aspersão com auxílio de pistola acoplada a motocompressor de ar e mantidas no escuro a $26^{\circ} \mathrm{C}$ com $100 \%$ de UR por 24 h. Após esse período, as plântulas foram transferidas para casa de vegetação sem controle de umidade, temperatura e fotoperíodo, aonde permaneceram até a avaliação da severidade. Aos dez dias após a inoculação, a proporção de área foliar necrosada nas plântulas foi determinada com auxílio do programa Quant $^{\circledR}$ de acordo com Araújo e STADNIK $(2011 ; 2013)$.

Foram retirados quatro discos da $2 .^{\mathrm{a}}$ e $3 .^{\mathrm{a}}$ folhas expandidas de plântulas de ambos os genótipos com auxílio de um vazador ( $8 \mathrm{~mm}$ de diâmetro) às 24,48 e 72 horas após a inoculação (HAI). Devido à influência da idade na suscetibilidade a MFG, as folhas superiores foram escolhidas, pois estas são mais suscetíveis do que as inferiores, mais velhas (ArAÚjo et al., 2008). Os discos foliares coletados para análise microscópica foram processados conforme metodologia descrita por Araújo e STADNiK (2011).

Para visualização do fungo, discos foliares de ambos os genótipos foram montados em lâminas de vidro e corados com azul de Aman em lactofenol. A germinaçáo foi determinada em 100 conídios sobre os discos foliares e expressa em percentual (ARaújo e STADNiK, 2011). Dos conídios germinados com apressório, avaliou-se a frequência de classes (\%) de conídios com um apressório, com um apressório mais um tubo germinativo e com mais de um apressório. Também, verificou-se a ocorrência de TAC em 500 conídios, conforme descrição de Roca, Read e Wheals, (2005) e Ishiakawa et al. (2010b). As estruturas de infecção do fungo foram fotografadas com uma câmera digital (modelo cyber-shot DSC-P93, Sony, Brasil) acoplada a um microscópio de luz binocular (modelo FWL1500, Feldmann Wild Leite, Brasil).

O delineamento experimental foi inteiramente casualizado com cinco repetições por tratamento, sendo que cada unidade experimental foi constituída de uma plântula por vaso. Para a avaliação do processo infeccioso, cada unidade constou de quatro discos por plântula. Dois experimentos independentes foram realizados em diferentes tempos, com resultados semelhantes, e um deles foi escolhido para representar os resultados. Os dados foram submetidos à análise de variância em esquema fatorial (genótipo $\mathrm{x}$ isolado, $2 \times 2$ ) e as médias comparadas pelos testes Tukey e $t(\mathrm{p}<0,05)$. Quando necessário para realização das análises estatísticas, os dados foram transformados para $\sqrt{x}_{\mathrm{x}}$. As análises estatísticas foram feitas no programa Statistica 6.0 - Stat Soft ${ }^{\mathbb{R}}$.

Somente o fator genótipo de macieira foi significativo na avaliação de severidade da MFG (Figura 1). Não houve diferença significativa de severidade em plântulas do mesmo genótipo, quando infectadas com distintos isolados de C. gloeosporioides (Figura 1). Plântulas do genótipo resistente não apresentaram sintomas, enquanto que as suscetíveis exibiram em média 11 e 10\% de área foliar necrosada, aos dez dias após a inoculação com os isolados MANE55 e MANE147 de C. gloeosporioides, respectivamente (Figura 1). Estes resultados são semelhantes aos obtidos por Araújo e STADNiK $(2011,2013)$, que também facilmente distinguiram fenótipos resistentes dos suscetíveis.

Somente o fator isolado de C. gloeosporioides foi significativo para todas as variáveis microscópicas analisadas

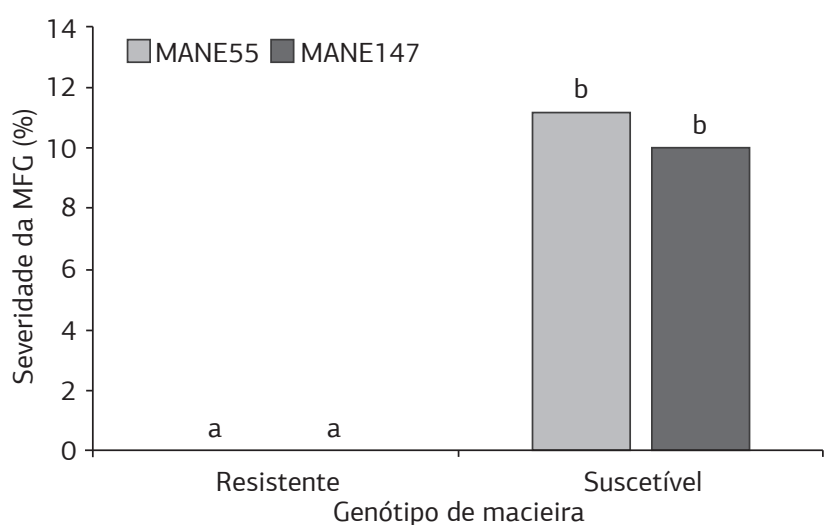

Figura 1. Severidade (\%) da Mancha foliar de Glomerella (MFG) aos 10 dias após a inoculaçáo com os isolados MANE55 e MANE147 de Colletotrichum gloeosporioides em plântulas de macieira de genótipo resistente e suscetível à doença. Colunas, seguidas pelas mesmas letras não diferem entre si pelo teste Tukey ao nível de $5 \%$ de probabilidade. 
(Tabela 1). Não houve diferença significativa na formação das estruturas de infecção de C. gloeosporioides, quando desenvolvidas em distintos genótipos de macieira (Tabela 1). Conídios germinados do isolado MANE55 de C. gloeosporioides formaram menos apressórios $( \pm 48 \%)$ nas folhas de ambos cultivares, mas apresentaram maior número de apressórios múltiplos $( \pm 135 \%)$ que o isolado MANE147 (Tabela 1). Os dois isolados apresentaram apressórios sésseis e pedicelados (Figura 2).

Outros estudos com Colletotrichum sp. também demonstraram que os eventos iniciais de penetração náo diferem em cultivares resistentes e suscetíveis a doenças (Ishikawava et al., 2010a; Araújo e Stadnik, 2011). Conídios de Colletotrichum emitem um tubo germinativo que se diferencia em apressório no hospedeiro e, caso o fungo não consiga infectar, pode formar um segundo apressório (Kolattukudy et al., 1995; Peres et al., 2005; IsHiakAwa et al., 2010a). O apressório é essencial para que Colletotrichum possa penetrar a cutícula e a parede celular do hospedeiro (Kolattukudy et al., 1995; Peres et al., 2005). Gonçalves e Stadnik (2012) verificaram que conídios de C. gloeosporioides formavam um segundo apressório, quando desenvolvidos em meios de cultura enriquecidos com polissacarídeos. Por outro lado, há relatos que isolados de C. gloeosporioides e C. musae que formam múltiplos apressórios são mais agressivos em frutos de abacate e banana, respectivamente (Flaishman e Kolattukudy, 1994; Kolattukudy et al., 1995).

No presente trabalho, apesar do isolado MANE55 apresentar menos conídios com apressório, isto parece não ter interferido na sua agressividade, já que a severidade das plântulas inoculadas com ambos isolados foi semelhante (Figura 1). Uma provável explicação para este fato é que, após a inoculação com C. gloeosporioides, algumas células da macieira exibem respostas de defesa (Araújo et al., 2008; Araújo e StadniK, 2011; 2013), impedindo a penetração pelo primeiro apressório. Assim, pode-se hipotetizar que o isolado MANE55 possuía maior capacidade genética, ou melhor estado nutricional que MANE147 para formaçáo de mais de um apressório por conídio na tentativa de infectar seu hospedeiro. Estas hipóteses podem ser consideradas, visto que $C$. gloeosporioides possui alta variabilidade genética (Gonzalez, SutTon e Correll, 2006) e tem a capacidade de formar um segundo apressório sob condiçóes nutricionais adequadas em meio de cultura (GonçALVES e STADNiK, 2012). Além disso, este estudo confirma a capacidade de C. gloeosporioides formar apressórios sésseis sobre folhas de macieira, conforme descrito por Gonçalves e STADNIK (2012) em condiçóes in vitro.

Foram observados TAC em conídios não germinados e germinados com e sem apressórios sobre lesóes da MFG em
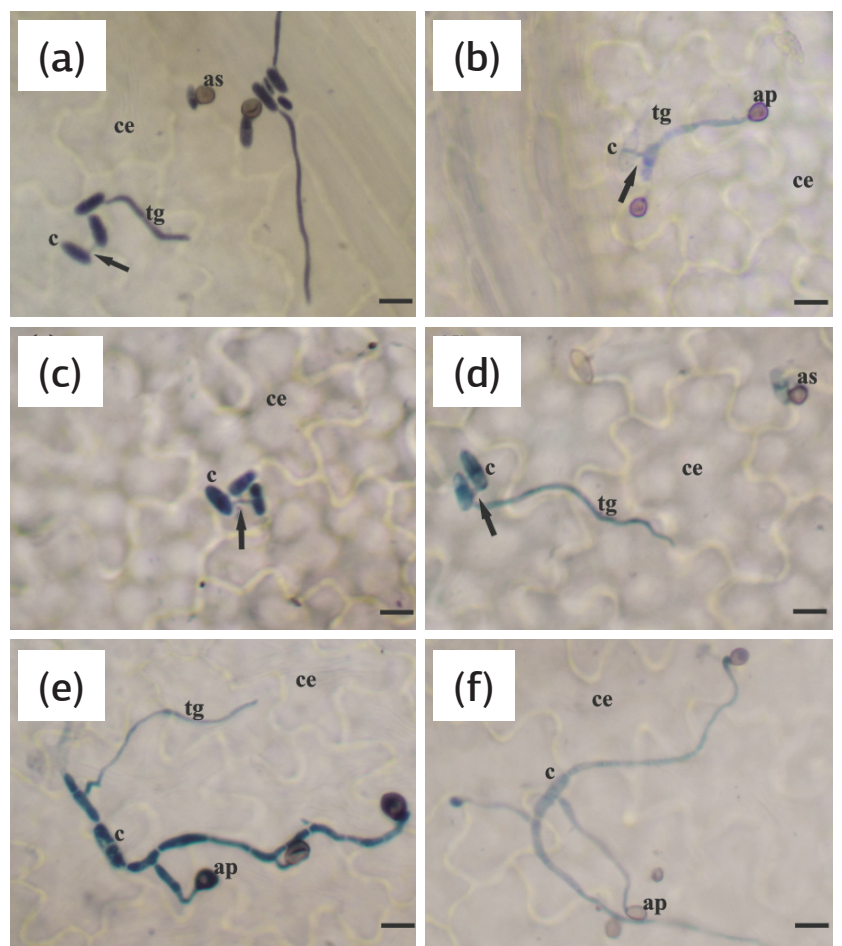

Figura 2. Micrografias de luz do processo infeccioso dos isolados MANE147 (a-d) e MANE55 (e, f) de Colletotrichum gloeosporioides na superfície adaxial de folhas de macieira às $24(\mathrm{a}, \mathrm{c}), 48(\mathrm{~b}, \mathrm{~d}) \mathrm{e}$ 72 (e, f) horas após a inoculação. (ap) apressório pedicelado; (as) apressório séssil; (c) conídio; (ce) células epidérmicas; (tg) tubo germinativo. Setas, tubos de anastomose conidiais. Barras $=10 \mu \mathrm{m}$.

Tabela 1. Frequência de conídios germinados com apressório na superfície adaxial de folhas de macieira de genótipo suscetível (S) ou resistente (R) à Mancha Foliar de Glomerella às 24, 48 e 72 horas após a inoculação (HAI) com os isolados MANE55 (M55) e MANE147 (M147) de Colletotrichum gloeosporioides

\begin{tabular}{|c|c|c|c|c|c|c|c|c|c|c|c|}
\hline \multirow{4}{*}{ HAI } & \multirow{4}{*}{ Genótipo } & \multicolumn{10}{|c|}{ Variáveis } \\
\hline & & \multirow{2}{*}{\multicolumn{2}{|c|}{ Conídios germinados (\%) }} & \multirow{2}{*}{\multicolumn{2}{|c|}{ Com apressório (\%) }} & \multicolumn{6}{|c|}{ Número de apressórios por conídio (\%) } \\
\hline & & & & & & \multicolumn{2}{|c|}{1} & \multicolumn{2}{|c|}{$1+$ TG } & \multicolumn{2}{|c|}{$>1$} \\
\hline & & M55 & M147 & M55 & M147 & M55 & M147 & M55 & M147 & M55 & M147 \\
\hline \multirow[t]{2}{*}{24} & S & $61,4 \mathrm{aA}$ & $72,4 \mathrm{aA}$ & $28,0 \mathrm{aB}$ & 82,0 aA & $90,0 \mathrm{aA}$ & $98,1 \mathrm{aA}$ & $10,0 \mathrm{aA}$ & $1,0 \mathrm{aB}$ & $0,0 \mathrm{aA}$ & $0,9 \mathrm{aA}$ \\
\hline & $\mathrm{R}$ & 53,6 aA & 66,3 aA & $31,0 \mathrm{aB}$ & $77,0 \mathrm{aA}$ & 95,6 aA & $98,1 \mathrm{aA}$ & $4,4 \mathrm{aA}$ & $0,8 \mathrm{aB}$ & $0,0 \mathrm{aA}$ & $1,1 \mathrm{aA}$ \\
\hline \multirow[t]{2}{*}{48} & S & 89,0 aA & $60,2 \mathrm{aB}$ & $56,0 \mathrm{aB}$ & 88,0 aA & $49,5 \mathrm{aB}$ & 99,6 aA & 24,8 aA & $0,4 \mathrm{aB}$ & 25,7 aA & $0,0 \mathrm{aB}$ \\
\hline & $\mathrm{R}$ & $81,0 \mathrm{aA}$ & $61,4 \mathrm{aB}$ & $46,0 \mathrm{aB}$ & 82,0 aA & $78,8 \mathrm{aB}$ & 98,0 aA & $16,1 \mathrm{aA}$ & $1,0 \mathrm{aB}$ & 5,1 bA & $1,0 \mathrm{aB}$ \\
\hline \multirow[t]{2}{*}{72} & S & $85,4 \mathrm{aA}$ & 85,3 aA & $53,0 \mathrm{aB}$ & $92,0 \mathrm{aA}$ & $51,8 \mathrm{aB}$ & 99,3 aA & $21,3 \mathrm{aA}$ & $0,6 \mathrm{aB}$ & 26,9 aA & $0,1 \mathrm{aB}$ \\
\hline & $\mathrm{R}$ & 90,3 aA & $82,2 \mathrm{aA}$ & $50,0 \mathrm{aB}$ & $84,0 \mathrm{aA}$ & $53,9 \mathrm{aB}$ & 99,3 aA & $20,4 \mathrm{aA}$ & $0,6 \mathrm{aB}$ & $25,7 \mathrm{aA}$ & $0,1 \mathrm{aB}$ \\
\hline
\end{tabular}

Dados de número de apressórios por conídio $(1+\mathrm{TG}$; 1$)$ foram transformados para $\sqrt{\mathrm{x}}$ antes da análise estatística. Para cada variável, médias seguidas pelas mesmas letras minúsculas na coluna e maiúsculas nas linhas não diferem entre si pelo teste t a $5 \%$ de probabilidade dentro de cada intervalo de tempo. 
macieira, para os dois isolados de C. gloeosporioides em todos os intervalos de tempo (Figura 2). No entanto, foi detectado maior frequência de TAC para o isolado MANE147 $(8,2 \%)$ do que para o MANE55 (1,5\%) (dados não mostrados), o que leva a hipotetizar que a capacidade de formaçáo de TAC seja afetada pelo genótipo do fungo. De fato, IsHIAKaWA et al. (2010b) verificaram que diferentes raças de C. lindemuthianum apresentavam diferentes taxas de TAC (até 26\%) in vitro. A fusão de TAC em Colletotrichum parece ocorrer em cerca de 10\% dos conídios presentes em acérvulos (Roca, ReAd e WhEALs, 2005). A importância da fusão de TAC em Colletotrichum é devido à capacidade de geração de variabilidade, já que este mecanismo facilita a THG (Roca, Read e Wheals, 2005; IshiakaWa et al., 2010a,b; Mehrabi et al., 2011). Por exemplo, em macieira, a "Gala" é suscetível, e a "Fuji" resistente à MFG (Araújo e StadniK, 2011; 2013). Contudo, ambas cultivares apresentam suscetibilidade a isolados de C. gloeosporioides que causam a podridáo amarga da maçá (Gonzalez, Sutton e Correll, 2006). Desta maneira, os TAC poderiam permitir a troca de material genético entre isolados causadores de ambas as doenças, podendo gerar novas raças do patógeno e/ou ampliação da gama de hospedeiro. No entanto, é importante salientar que a técnica de microscopia utilizada no presente trabalho permite apenas detectar a presença de TAC entre os conídios de C. gloeosporioides, sendo necessários novos estudos para confirmar a troca de núcleos e THG.

Em suma, este é o primeiro relato da ocorrência de múltiplos apressórios e TAC no processo infeccioso de isolados de C. gloeosporioides sobre folhas de macieira.

\section{AGRADECIMENTOS}

Os autores agradecem a Coordenação de Aperfeiçoamento de Pessoal de Nível Superior - CAPES pela concessão da bolsa de estudos ao primeiro autor. MJS agradece ao Conselho Nacional de Desenvolvimento Científico e Tecnológico $(\mathrm{CNPq})$ pela bolsa de produtividade. A Dr. ${ }^{a}$ Rosa Valdebenito-Sanhueza pelo fornecimento de sementes e isolado fúngico (MANE55).

\section{REFERÊNCIAS}

ARAÚJO, L.; BORSATO, L.C.; VALDEBENITO-SANHUEZA, R.M.; STADNIK, M.J. Fosfito de potássio e ulvana no controle da mancha foliar da gala em macieira. Tropical Plant Pathology, v.33, p.74-80, 2008. DOI: 10.1590/S1982-56762008000200009

ARAÚJO, L.; STADNIK, M.J. Processo infeccioso e atividade de enzimas em plântulas de macieira de genótipo resistente ou suscetível à mancha foliar de Glomerella causada por Colletotrichum gloeosporioides. Tropical Plant Pathology, v.36, p.241-248, 2011.

ARAÚJO, L.; STADNIK, M.J. Cultivar-specific and ulvaninduced resistance of apple plants to Glomerella leaf spot are associated with enhanced activity of peroxidases. Acta Scientiarum Agronomy, v.35, p.287-293, 2013. DOI: 10.4025/actasciagron. v35i3.16174

BECKER, W.F.; KATSURAYAMA, Y.; BONETI, J.I.S. Mancha foliar da gala: principal doença de verâo da cultura da macieira. Agropecuária Catarinense, v.13, p.14-20, 2000.

FLAISHMAN, M.A.; KOLATTUKUDY, P.E. Timing of fungal invasion using host's ripening hormone as a signal. Proceedings of the National Academy of Sciences USA, v.91, p.6579-6583, 1994. DOI: $10.1073 /$ pnas.91.14.6579

GONÇALVES, A.E.; STADNIK, M.J. Interferência de ulvana no desenvolvimento e melanização de apressórios de Colletotrichum gloeosporioides. Tropical Plant Pathology, v.37, p.431-437, 2012. DOI: $10.1590 /$ S1982-56762012000600010

GONZALEZ, E.; SUTTON, T.B.; CORRELL, J.C. Clarification of the etiology of Glomerella leaf spot and bitter rot of apple caused by Colletotrichum spp. based on morphology and genetic, molecular, and pathogenicity tests. Phytopathology, v.96, p.982992, 2006.

ISHIKAWA, F.H.; BARCELOS, Q.L.; ALVES, E.; CAMARGO, J.O.A.; SOUZA E.A. Symptoms and prepenetration events associated with the infection of common bean by the anamorph and teleomorph of Glomerella cingulata f.sp. phaseoli. Phytopathology, v.158, p.270-277, 2010a.

ISHIKAWA, F.H.; SOUZA, E.A.; READ, N.D.; ROCA, M.G. Live-cell imaging of conidial fusion in the bean pathogen, Colletotrichum lindemuthianum. Fungal Biology, v.114, p.2-9, 2010b. DOI: 10.1016/j.funbio.2009.11.006

KOLATTUKUDY, P.E.; ROGERS, L.M.; LI, D.; HWANG, C.S.; FLAISHMAN, M.A. Surface signaling in pathogenesis. Proceedings of the National Academy of Sciences USA, v.92, p.4080-4087, 1995. DOI: $10.1073 /$ pnas.92.10.4080

MEHRABI, R.; BAHKALI, A. H.; ABD-ELSALAM, K.A.; MOSLEM, M.; M'BAREK, S. B.; GOHARI, A.M.; JASHNI, M.K.; STERGIOPOULOS, L.; KEMA, G.H.J.; WIT, P.J.G.M. Horizontal gene and chromosome transfer in plant pathogenic fungi affecting host range. FEMS Microbioly Review, v.35, p.542554, 2011. DOI: /10.1111/j.1574-6976.2010.00263.x

PERES, N.A.; TIMMER, L.W.; ADASKAVEG, J.E.; CORRELL, J.C. Lifestyles of Colletotrichum acutatum. Review of Plant Disease, v.89, p.784-796, 2005. DOI: 10.1094/PD-89-0784

ROCA, M.G.; READ, N.D.; WHEALS A.E. Conidial anastomosis tubes in filamentous fungi. FEMS Microbiology Letters, v.249, p.191-198, 2005. 